\title{
ORIGINALARTICLE
}

\section{Determination of number of Extracranial and Intracranial Atherosclerotic Arterial Stenosis in Patients of Ischemic Stroke with Diabetes Mellitus under DSA Evaluation}

\author{
MOHAMMAD SHAH JAHIRUL HOQUE CHOWDHURY ${ }^{1}$, MURSHED BAQUI ${ }^{2}$, \\ MD TOWHIDUL ISLAM CHOWDHURY ${ }^{3}$, NAYEEM AHMED ${ }^{4}$, MD NAHIDUL ISLAM ${ }^{5}$, \\ SUDIPTA KUMAR MUKHERJEE ${ }^{6}$, MOHIBUR RAHMAN ${ }^{7}$, SHARIF UDDIN KHAN ${ }^{8}$, \\ QUAZI DEEN MOHAMMAD ${ }^{9}$
}

\begin{abstract}
:
Objective: To evaluate the solitary \& multiple site of extracranial and intracranial atherosclerotic arterial stenosis in patients of ischemic stroke with diabetes mellitus.

Methodology: This retrospective observational study was conducted among the patients having ischemic stroke with diabetes mellitus who were admitted in Dhaka Medical College \& Hospital (DMCH) out patient department during March 2010 to February 2011. A total of 30 patients with ischemic stroke and diabetes mellitus were included in the study. CT scan of brain was done to every patient to confirm the diagnosis. Digital subtraction angiography was performed for complete evaluation.

Result: The mean ( $\pm S D$ ) age was $57.9 \pm 9.2$ years with a range from 43 to 80 years and male female ratio was 29:1. Among 21 patients with extracranial stenosis, either single, double and triple or more lesions were found in $53.3 \%, 85.7 \%$ and $87.5 \%$ of patients respectively. Again among 9 patients with intracranial stenosis, it was observed that $46.7 \%$ of patients had single lesion stenosis, $14.3 \%$ of patient had double lesion stenosis and $12.5 \%$ of patients had triple or more lesion stenosis. Double (85.7\%) and triple (87.5\%) lesions were significantly $(p<0.05)$ higher in extracranial stenosis compared to intracranial stenosis (14.3\% and $12.5 \%$ respectively). Most (78.9\%) of the patients had $>70 \%$ stenosis in extracranial arteries and $21.1 \%$ in intracranial arteries. Patients with $>70 \%$ stenosis were significantly $(p<0.05)$ higher in extracranial arteries.

Conclusion: A conclusion can be made from the above mentioned result that occurrence of multiple site of lesions and more severe stenosis occurred more in extracranial group than in intracranial group of ischemic stroke patients among diabetic population of Bangladesh.
\end{abstract}

Introduction:

Stroke is a medical emergency and can cause permanent neurological damage, even death. It is the leading cause of adult disability in the United States and Europe and second cause of death worldwide ${ }^{1}$. The incidence and mortality rate due

1. Assistant Professor (Resident Physician), National Institute of Neurosciences and Hospital, Sher-E- Bangla Nagar, Dhaka.

2. Medical Officer, National Institute of Neurosciences and Hospital, Sher-E- Bangla Nagar, Dhaka.

3. Assistant Professor, National Institute of Neurosciences and Hospital, Sher-E- Bangla Nagar, Dhaka.

4. National Institute of Neurosciences and Hospital, Sher-E- Bangla Nagar, Dhaka.

5. Registrar, National Institute of Neurosciences and Hospital, Sher-E- Bangla Nagar, Dhaka.

6. Assistant Professor, Paediatric Neurosurgery, National Institute of Neurosciences and Hospital, Sher-E- Bangla Nagar, Dhaka.

7. Assistant Professor, National Institute of Neurosciences and Hospital, Sher-E- Bangla Nagar, Dhaka.

8. Associate Professor, Dept. of Neurology, Dhaka Medical College \& Hospital.

9. Professor \& Head, Dept. of Neurology, Dhaka Medical College \& Hospital 
to stroke is higher in Asians than that in Whites. Risk factors for stroke includes diabetes mellitus, advanced age, hypertension, previous stroke or transient ischaemic attack (TIA), high cholesterol, cigarette smoking and atrial fibrillation ${ }^{2,3}$.

An ischemic stroke typically results from blockage of an artery that supplies the brain, most commonly a branch of one of the internal carotid arteries. Commonly, blockages are blood clots (thrombi) or pieces of fatty deposits (atheromas or plaques) due to atherosclerosis ${ }^{4}$.The pathological changes associated with atherosclerosis are several-fold more frequent in person with diabetes. In diabetic people, atheromatous lesions occur earlier in life and are more extensive and severe ${ }^{5}$. It is now well established that atherosclerotic disease (atheroma) is a strong and independent risk factor for ischemic stroke. The thickness of the atheroma and its morphology (protruding, ulcerated, calcified or mobile plaque) are both strongly related to increased risk of ischemic stroke. Plaques $>4 \mathrm{~mm}$ thick are presumed to be of very high risk. Thus, the burden of atherosclerotic disease has been directly implicated in the increased risk for ischemic stroke. Intracranial carotid lesions are reported to be more common than extracranial carotid lesions among Japanese, Korean, Chinese and African-American as documented by angiographic and autopsy studies in stroke patients, which is in sharp contrast to the pattern of cerebral atherosclerosis in whites ${ }^{6-8}$.

This study was aimed to evaluate distribution of intracranial and extracranial atherosclerotic arterial stenosis in patients of ischemic stroke with diabetes mellitus by digital subtraction angiography (DSA) though it is invasive, relatively costly and uses radio contrast dye. This will also evaluate the relationship of diabetes mellitus with intracranial and extracranial atherosclerotic arterial stenosis in ischemic stroke patients. This study will help the patient of ischemic stroke with diabetes mellitus among Bangladeshi population regarding their etiological evaluation with management.

\section{Methodology : \\ Study Design : Retrospective cross-sectional observational study.}

Place of Study : Department of Neurology, Dhaka Medical College Hospital (DMCH), Dhaka.
Duration of Study : March 2010 to February 2011.

Sample Size : Sample size was 30. Patients of ischemic stroke with diabetes mellitus were included.

Sampling Procedure : Non- random and purposive.

Inclusion Criteria : Patients of ischemic stroke with diabetes mellitus who were clinically suggestive and confirmed by CT scan of Brain and patients having stenosis of $>50 \%$ stenosis were considered significant and were included in this study. Other inclsion criteria were investigations (e.g. Protein C, Protein S, Antithrombin III, Transthoracic and Transoesophageal Echocardiogram), which were within normal limit and adult patients with age more than 40 years of both gender.

Exclusion Criteria: Hemorrhagic stroke, nondiabetic patients, mixed type stenosis (both extracranial and intracranial stenosis) evaluated by DSA and patients who did not give consent to take part in the study.

Analysis of data : Statistical analysis was performed using SPSS 16.0 programme. Data was defined as mean ( \pm standard deviation), frequency distribution and percentage. $Z$ test was used for proportion test. $P$ values $<0.05$ was considered to be statistically significant.

\section{Results :}

The mean $( \pm S D)$ age was $57.9 \pm 9.2$ years with range from 43 to 80 years( Table-I) and male female ratio was 29:1. Among 21 patients with extracranial stenosis, single, double and triple or more lesions were found in $8(53.3 \%), 6(85.7 \%)$ and 7 (87.5\%) patients respectively( Table II). On the other hand, among 9 patients with intracranial stenosis, it was observed that 7 patients $(46.7 \%)$ had single lesion stenosis, 1 patient $(14.3 \%)$ had double lesion stenosis and 1 patient $(12.5 \%)$ had triple or more lesion stenosis. Double and triple lesions were significantly $(p<0.05)$ higher in extracranial stenosis in comparison to intracranial stenosis. Moreover 15 patients $(78.9 \%)$ had $>70 \%$ stenosis in extracranial arteries and 4 patients $(21.1 \%)$ had $>70 \%$ stenosis in intracranial arteries. $51 \%$ to $70 \%$ of stenosis was found in $6(54.5 \%)$ patients in extracranial sites and in $5(21.1 \%)$ patients in intracranial sites. Patients with $>70 \%$ stenosis were significantly $(p<0.05)$ higher in extracranial arteries( Table III). 
Table-I

Distribution of the respondents'

age by group $(n=30)$

\begin{tabular}{lcc}
\hline Age (in years) & Number of patients $(\mathrm{n}=30)$ & Percentage \\
\hline $41-50$ & 8 & 26.7 \\
$51-60$ & 11 & 36.7 \\
$61-70$ & 10 & 33.3 \\
$71-80$ & 1 & 3.3 \\
Mean \pm SD & 57.9 & \pm 9.2 \\
Range (Mean-Max) & $(43$ & $-80)$ \\
\hline
\end{tabular}

Table-II

Distribution of the respondents' according to the number of lesions $(n=30)$

\begin{tabular}{lcccccc}
\hline $\begin{array}{l}\text { Number of } \\
\text { Lesions }\end{array}$ & $\begin{array}{c}\text { Extracranial } \\
\text { Stenosis }(\mathrm{n}=21)\end{array}$ & \multicolumn{5}{c}{$\begin{array}{c}\text { Intracranial } \\
\text { Stenosis(n=9) }\end{array}$} \\
& $\mathrm{N}$ & $\%$ & $\mathrm{n}$ & $\%$ & & Z value \\
\hline Single & 8 & 53.3 & 7 & 46.7 & 0.36 & $0.054^{\mathrm{ns}}$ \\
Double & 6 & 85.7 & 1 & 14.3 & 5.58 & $0.001^{\mathrm{s}}$ \\
Triple or more & 7 & 87.5 & 1 & 12.5 & 6.21 & $0.001^{\mathrm{s}}$ \\
\hline
\end{tabular}

Table-III

Distribution of the respondents' according to the significant (i.e. $>50 \%)$ degree of stenosis $(n=30)$

\begin{tabular}{lcccccc}
\hline $\begin{array}{l}\text { Percentage of } \\
\text { stenosis }\end{array}$ & $\begin{array}{c}\text { Extracranial } \\
\text { Stenosis }(\mathrm{n}=21)\end{array}$ & \multicolumn{3}{c}{$\begin{array}{c}\text { Intracranial } \\
\text { Stenosis }(\mathrm{n}=9)\end{array}$} & Z value & P value \\
& $\mathrm{N}$ & $\%$ & $\mathrm{~N}$ & $\%$ & & \\
\hline $51-70$ & 6 & 54.5 & 5 & 45.5 & 0.42 & $>0.05^{\text {ns }}$ \\
$>70$ & 15 & 78.9 & 4 & 21.1 & 4.37 & $0.001^{\mathrm{s}}$ \\
\hline
\end{tabular}

\section{Discussion:}

This retrospective observational study was carried out with an aim to evaluate the solitary \& multiple site of extracranial and intracranial atherosclerotic arterial stenosis by digital subtraction angiography in 30 patients of ischemic stroke with diabetes mellitus who attended in the out-patient department of Neurology, Dhaka Medical College Hospital (DMCH) during the period of March 2010 to February 2011.

Risk factors more commonly observed were IHD, dyslipidaemia, H/O TIA, hypertension, obesity and smoking. A study in Hong Kong China observed similar risk factors including hypertension
(71.0\%), smoking (38.7\%), previous $\mathrm{H} / \mathrm{O}$ stroke $(51.6 \%)$ and IHD $(19.4 \%)^{9}$.Another study reported hypertension and diabetes mellitus as risk factors associated only with intracranial atherosclerosis $(p<0.001)$, whereas ischemic heart disease was associated with atherosclerosis in both the intracranial and extracranial $(p=0.012)$ vessels $(p<0.001)^{10}$. Smoking was associated with narrowing of the extracranial vessels only $(p=0.001)$. A study on Korean patients showed diabetes mellitus as only significant factor associated with combined intracranial atherosclerosis and extracranial carotid artery disease $^{8}$. These findings are comparable with the present study regarding the risk factors. 
Regarding 2 hours after breakfast blood sugar, most of the 26 patients $(86.7 \%)$ had blood sugar level between 7.8 to $20 \mathrm{mmol} / \mathrm{L}, 3$ patients $(10.0 \%)$ had $>20 \mathrm{mmol} / \mathrm{L}$ and only 1 patient (3.3\%) had normal ( $<7.7 \mathrm{mmol} / \mathrm{L}$ ) and regarding level of $\mathrm{HbA}_{1 \mathrm{C}}$ (Glycated Haemoglobin), a higher portion of 18 patients $(60.0 \%)$ had $>7 \%$ followed by 11 patients $(36.7 \%)$ had $6.5 \%$ to $7 \%$ and only 1 patient (3.3\%) had normal level. That is most of the patients had uncontrolled diabetes mellitus in this study. Data from the Northern Manhattan Stroke study reported that patients with intracranial atherosclerosis had a higher prevalence of diabetes $(67 \%)$ when compared to those with extracranial atherosclerosis or non-atherosclerotic $(60 \%$ and $48 \%$ respectively $)^{11}$.

In this study, single lesions were found among $53.3 \%$ and $46.7 \%$ in extracranial stenosis and intracranial stenosis respectively. Double (85.7\%) and triple $(87.5 \%)$ lesions were significantly $(p<0.05)$ higher in extracranial stenosis with compared to intracranial stenosis $(14.3 \%$ and $12.5 \%$ respectively). Similarly two separate studies showed that single-stenosis was more common in intracranial stenosis and multiple stenoses were significantly higher in extracranial stenosis ${ }^{8,12}$.

Regarding the degree arterial diameter of stenosis it was observed that, $>70 \%$ stenosis had in extracranial sites in most $(78.9 \%)$ of the patients and $21.1 \%$ of patients in intracranial sites. $51 \%$ to $70 \%$ of stenosis was found in $54.5 \%$ of patients in extracranial sites and $21.1 \%$ of patients in intracranial sites. Patients with $>70 \%$ stenosis was significantly $(p<0.05)$ higher in extracranial stenosis. Similar findings were observed in a study on 'Pattern of atherosclerotic carotid stenosis in Korean patients with stroke' that severe stenosis was in extracranial stenosis ${ }^{12}$.

\section{References:}

1. Feigin VL. "Stroke epidemiology in the developing world". Lance; 2005;365 (9478): 2160-1.

2. Safeer M, Tariq M, Rehman U. 'Frequency of risk factors of cerebral Infarction in stroke patients. A study of 100 Cases in naseer teaching hospital, Peshawar'. Pak J Med Sci 2008; 24 (1):109-13.

3. Sacco RL, Benjamin EJ, Broderick JP, Dyken Mark, Easton JD. 1997, 'Risk factors'. Stroke 1997;28: 1507-17.

4. Gupta V, Nanda NC. Racial Differences in Thoracic Aorta Atherosclerosis Among Ischemic Stroke Patients. Strok 2003; 34(12):408-12.

5. Frier BM, Fisher M. Diabetes mellitus In: Colledge NR, Walker BR, Ralston SH, editors. Davidson's Principles and Practice of Medicine. $21^{\text {st }}$ edn. Edinburg: Churchill Livingstone 2010; 795-834.

6. Liu HM, Tu YK, Yip PK, Su CT. Evaluation of intracranial and extracranial carotid stenoocclusive diseases in Taiwan Chinese patients with MR angiography: preliminary experience. Stroke 1996; 27:650-3.

7. Uehara T. Frequency and clinical correlates of occlusive lesions of cerebral arteries in Japanese patients without stroke: evaluation by MR angiography. Cerebrovasecular Disease 1998; 8: 267-72.

8. Lee SJ, Cho SJ Moon HS, Shon YM, Lee $\mathrm{KH}$, Kim DI . Combined extracranial and intracranial atherosclerosis in Korean patients. Arch Neurol 2003; 60(11):1561-4.

9. Huang CY, Chan FL, Yu YL, Woo E and Chin D.'Cerebrovascular Disease in Hong Kong Chinese'. Stroke 1990;1: 230-35.

10. Leung SY, Thomas H.K. Yuen ST, Lauder J., Ho FCS. 'Pattern of Cerebral Atherosclerosis in Hong Kong Chinese'. Stroke 1993; 24 : 779-86

11. Rincon F, Sacco RL, Kranwinkel G. Incidence and risk factors of intracranial atherosclerotic Stroke: The Northern Manhattan Stroke Study. Cerebrovascular Disease 2009; 28: 65-71.

12. Suh DC, Lee SH, Kim KR, Park ST, Lim SM, 'Pattern of atherosclerotic carotid stenosis in korean patients with stroke: Different involment of intracranial versus extraceranial vessels'. Am J of Neuroradiology; 2003; 24:239-44. 